\title{
The Endothelial Glycocalyx Prefers Albumin for Evoking Shear Stress-Induced, Nitric Oxide-Mediated Coronary Dilatation
}

\author{
Matthias Jacob ${ }^{a, b} \quad$ Markus Rehm ${ }^{a}$ Michael Loetsch ${ }^{b}$ Joern O. Paul ${ }^{b}$ \\ Dirk Bruegger $^{a} \quad$ Ulrich Welsch $^{c}$ Peter Conzen ${ }^{a}$ Bernhard F. Becker ${ }^{b}$ \\ ${ }^{\mathrm{a} C l i n i c}$ of Anesthesiology and Departments of ${ }^{\mathrm{b}}$ Physiology and ${ }^{\mathrm{c}}$ Anatomy, Ludwig-Maximilians-University Munich, \\ Munich, Germany
}

\section{Key Words}

Endothelial glycocalyx $\cdot$ Nitric oxide $\cdot$ Albumin $\cdot$ Shear stress $\cdot$ Hydroxyethyl starch $\cdot$ Coronary vasodilatation . Dynamic viscosity

\begin{abstract}
Background: Shear stress induces coronary dilatation via production of nitric oxide (NO). This should involve the endothelial glycocalyx (EG). A greater effect was expected of albumin versus hydroxyethyl starch (HES) perfusion, because albumin seals coronary leaks more effectively than HES in an EG-dependent way. Methods: Isolated hearts (guinea pigs) were perfused at constant pressure with KrebsHenseleit buffer augmented with $1 / 3$ volume $5 \%$ human albumin or $6 \%$ HES (200/0.5 or $450 / 0.7)$. Coronary flow was also determined after EG digestion (heparinase) and with nitro-L-arginine (NO-L-Ag). Results: Coronary flow (9.50 \pm $1.09,5.10 \pm 0.49,4.87 \pm 1.19$ and $4.15 \pm 0.09 \mathrm{ml} / \mathrm{min} / \mathrm{g}$ for 'albumin', 'HES 200', 'HES 450' and 'control', respectively, $\mathrm{n}=$ 5-6) did not correlate with perfusate viscosity $(0.83,1.02$, 1.24 and $0.77 \mathrm{CP}$, respectively). NO-L-Ag and heparinase diminished dilatation by albumin, but not additively. Alone NO-L-Ag suppressed coronary flow during infusion of HES
\end{abstract}

M. Jacob and M. Rehm contributed equally to this study.
450. Electron microscopy revealed a coronary EG of $300 \mathrm{~nm}$, reduced to $20 \mathrm{~nm}$ after heparinase. Cultured endothelial cells possessed an EG of $20 \mathrm{~nm}$ to begin with. Conclusions: Albumin induces greater endothelial shear stress than HES, despite lower viscosity, provided the EG contains negative groups. HES 450 causes some NO-mediated dilatation via even a rudimentary EG. Cultured endothelial cells express only a rudimentary glycocalyx, limiting their usefulness as a model system.

Copyright $\odot 2007$ S. Karger AG, Basel

\section{Introduction}

The physiological importance of the endothelial glycocalyx (EG) had been ignored for many years. Modern preparation and staining techniques, however, have revealed a glycocalyx with a relevant thickness ranging from 0.3 to more than $1.0 \mu \mathrm{m}[1-5]$ throughout the vascular bed. This EG consists of extracellular domains of molecules like transmembrane syndecans and membrane-bound glypicans that both contain many covalently bound, negatively charged heparan sulfate and chondroitin sulfate groups [6]. The observation of intercalated plasma components, mainly albumin, led to the modern concept of the endothelial surface layer (ESL) which denies access of blood cells and large molecules to the en-

\section{KARGER \\ Fax +41613061234 E-Mail karger@karger.ch} www.karger.com
(C) 2007 S. Karger AG, Basel $1018-1172 / 07 / 0446-0435 \$ 23.50 / 0$

Accessible online at: www.karger.com/jvr
Dr. med. Matthias Jacob

Clinic of Anesthesiology, Ludwig-Maximilians-University Munich

Nussbaumstrasse 20, DE-80336 Munich (Germany)

Tel. +49 895160 2695, Fax +498951604446

E-Mail matthias.jacob@med.uni-muenchen.de 
dothelial surface [6-9] and, under physiological circumstances, likely covers adhesion molecules like selectins and integrins $[10,11]$, preventing pathological adhesiveness of the vascular wall [12]. Consequently, several important properties are to be attributed to the EG: it is involved in inflammatory processes and immune reactions $[13,14]$ and has been identified as a competent barrier against extravasation of fluids and colloids [4, 8, 15-17]. Other work suggested that the EG should play a key role in mediating shear stress to the endothelial surface and in triggering the production of vasoregulatory agents, mainly nitric oxide (NO) [18-23].

While the intracellular signaling pathway of shear stress-induced vasodilatation is well explored [24], the transduction of this stress to the endothelial surface remains rather unclear. The production of $\mathrm{NO}$, catalyzed by endothelial NO synthase, responds, according to experiments with monolayers of endothelial cells from human umbilical vein (HUVEC) and bovine aorta, in a biphasic manner to shear stress $[18,19,21]$. An initial rapid production phase ( $\mathrm{G}$ protein and $\mathrm{Ca}^{2+}$-dependent, influenced by rate of change of shear more than by the absolute shear level) is followed by a phase of lower production of $\mathrm{NO}$ ( $\mathrm{G}$ protein and $\mathrm{Ca}^{2+}$-independent, influenced by the absolute shear level [21]).

Most of the studies dealing with NO release induced by shear stress, however, are limited by the employed experimental model, i.e., cultured endothelial cells, presumably possessing only a rudimentary EG not comparable to the endothelial cell surface in vivo $[18,19]$. Additionally, this model does not deliver any functional data to quantify the effect of an applied shear stress on vascular flow, the main objective of releasing NO. Also, the ability of specified colloids to transmit shear stress to the endothelial cells via the individually generated ESL has not been compared quantitatively in situ.

In recent work on the isolated guinea pig heart, we substantiated that the role of colloids concerning vascular permeability depends predominantly on their ability to interact with the EG to form an ESL $[8,17]$. We observed an impressive sealing effect of human albumin during perfusion under constant flow, a mode in which the coronary system was able to alleviate shear stress by dilating.

The aim of the current study was to compare the functional impact of albumin and artificial colloids on vasodilatation induced by shear stress in the whole organ model. Due to its interaction with the EG we expected albumin to be more effective than artificial alternatives. In order to augment shear stress-induced vasodilatation, constant pressure perfusion of the coronary system was implemented. Because coronary endothelial cells in situ possess a glycocalyx of some 200-300 nm thickness [4, 8, 16], we additionally checked for the presence of an EG in confluent, cultured HUVECs, one of the most common 'artificial' models of the intravascular surface.

\section{Methods}

\section{Heart Preparation}

Guinea pig hearts were isolated and perfused in a modified Langendorff mode at constant perfusion pressure of $80 \mathrm{~cm} \mathrm{H}_{2} \mathrm{O}$ and at $37^{\circ} \mathrm{C}$ with modified Krebs-Henseleit buffer (KHB) as described elsewhere $[4,8,25]$.

\section{Experimental Protocols}

Experimental protocols are outlined in figure 1.

\section{Control Groups}

Time-matched vehicle control values were measured during infusion of $1 / 3$ volume of $0.9 \%$ saline ('control' group), after additional pretreatment with heparinase ('control heparinase' group), or during additional application of nitro-L-arginine (NO$\mathrm{L}-\mathrm{Ag}$ ), a substance known to block the endothelial NO synthase ('control NO-L-Ag' group; $\mathrm{n}=5$ each).

\section{Colloid Groups with Intact Glycocalyx}

Three different, clinically relevant colloids were added to KHB ( $1 / 3$ volume via the aortic feed line): $5 \%$ human albumin, $6 \%$ hydroxyethyl starch (HES) 200, and 6\% HES 450. The resulting groups were termed 'albumin', 'HES 200' and 'HES 450' ( $\mathrm{n}=5,6$ and 5 , respectively).

Colloid Groups after Heparinase Pretreatment, NO-L-Ag Application, or Combined Intervention

We performed the same experiments as before, but after pretreatment of hearts with heparinase ('albumin + H', 'HES $200+$ $H$ ' and 'HES $450+H$ ' groups; $n=5,6$ and 5, respectively). In 'albumin + NO-L-Ag' and 'HES $450+$ NO-L-Ag' groups $(n=8$ and 5 , respectively), we infused NO-L-Ag during replacement of $1 / 3$ volume of KHB with $5 \%$ human albumin or $6 \%$ HES 450 (phase III). In two further groups, hearts pretreated with heparinase (phase IIA) received NO-L-Ag in addition to $1 / 3$ volume $5 \%$ human albumin or HES 450 ('albumin + NO-L-Ag + H' and 'HES $450+$ NO-L-Ag + H'; n = 5 each).

\section{Electron Microscopy of Hearts}

Two additional hearts in each group, treated in the same way as described in the respective protocols, were prepared for electron microscopy. This was performed in modification of the method of Vogel et al. [26], as described elsewhere $[8,16]$ and relied primarily on stabilization of the glycocalyx with the polyvalent cation lanthanum $\left(\mathrm{La}^{3+}\right)$, which binds to the negative charges (heparan and chondroitin sulfates). Accordingly, the glyceal structure visualized in this manner does not entirely reflect the natural state, presumably appearing more orderly and more rigid that in vivo. However, it allows a quantitative estimation of the thickness of the layer. 


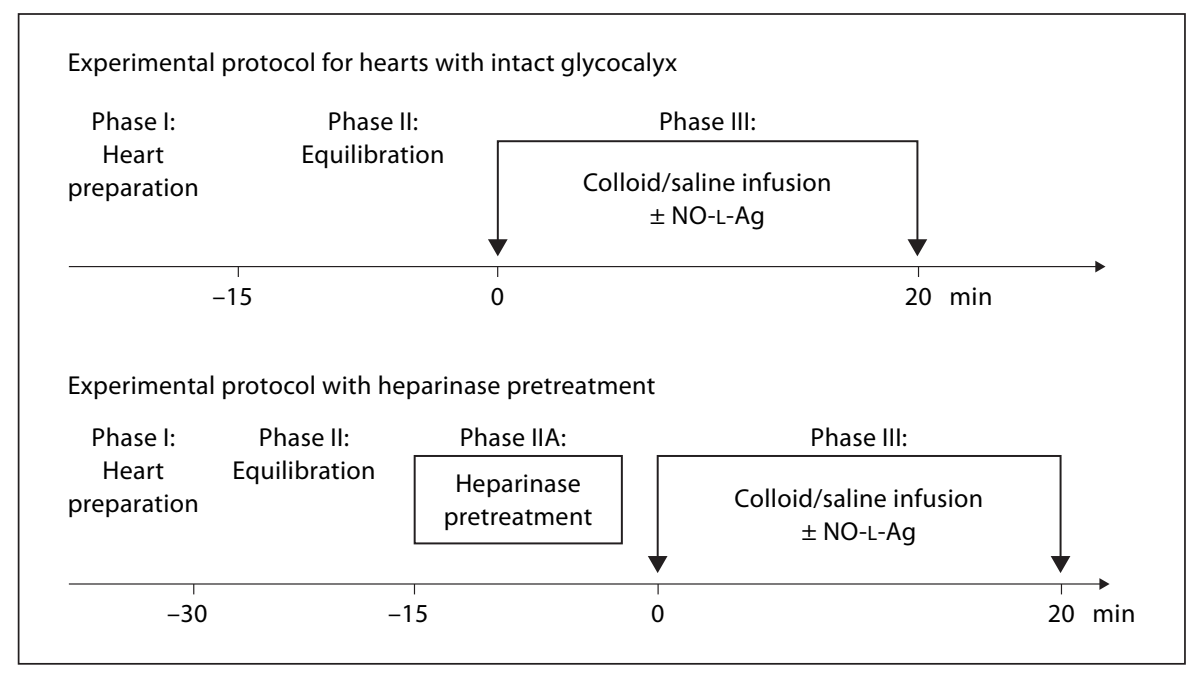

Fig. 1. Experimental protocols. Hearts were perfused with KHB from the onset of preparation during phases I (preparation, 15 min), II (equilibration, $15 \mathrm{~min}$ ), and IIA (optional heparinase pretreatment). During phase III, 1/3 volume KHB was replaced by isotonic saline (vehicle control), or by a solution of one of three different types of colloids. Constant application was achieved by repeatedly measuring the total coronary inflow and manually adjusting the rate of infusion. Optional application of NO-L-Ag $\left(10^{-5} \mathrm{M}\right)$ was performed throughout phase III in the respective

During electron-microscopic examination (Philips CM 10), whole capillary profiles were photographed systematically so that all capillaries in a section were photographed with the exception of those which were collapsed. This is justified because only capillaries with an open lumen provide a guarantee of having been perfused and uniformly stained with the glycocalyx tracer. Only in these is it possible to assess the thickness of the layer. The photographed capillaries presented here reflect the general and fairly uniform changes seen in the respective perfusion groups. Black and white images of approximately 50 capillaries of at least two hearts of each group were compiled. Electron-microscopic views were assessed qualitatively only.

\section{Cultivation and Electron Microscopy of HUVEC}

Endothelial cells freshly isolated from human umbilical veins (2nd passage) were seeded onto $\mu$-slides (IBIDI, Munich, Germany) and grown to three stages of maturity: nonconfluent, confluent and onset of capillarization. HUVEC monolayers $(n=5)$ were prepared for electron microscopy in a manner comparable to that described above for the hearts at the end of the experimental protocols.

\section{Statistical Analysis}

All data are presented as mean $\pm \mathrm{SD}$, with $\mathrm{n}$ indicating the number of experiments. Comparisons were made using analysis of variance. Post hoc testing was performed using the StudentNewman-Keuls method for multiple comparisons. A p value less than 0.05 was considered to be significant.

Glycocalyx-Mediated Coronary

Dilatation groups. Despite additional infusion of $1 / 3$ volume of ungassed solutions to the $\mathrm{KHB}$, the resulting perfusate reached an oxygen tension between 390 and $420 \mathrm{~mm} \mathrm{Hg}$ in all hearts. According to previous experiments, this represented a 'luxury oxygenation', never limiting oxygen consumption. Coronary flow was measured after equilibration (basal value) and at 1, 2, 3, 4, 6, 8, 10, 15 and $20 \mathrm{~min}$ of phase III in each protocol. Heparinase pretreatment: application of a total of 10 IU of heparinase/15 min during optional phase IIA.

\section{Results}

Table 1 provides an overall listing of coronary flow during control conditions ( $1 / 3$ volume of $0.9 \%$ saline added to the Krebs-Henseleit perfusate). In the absence of any further intervention, there was no time-dependent alteration in coronary vascular tone over the 20 -min period of observation. While heparinase pretreatment did not cause any measurable change in coronary flow, a slight decrease developed with time during NO-L-Ag infusion, indicating that this intervention is able to increase basal vascular tone even in a colloid-free perfusion mode. The effect was significant from the 6th minute of application onward.

Coronary flow did not change in the saline group, which serves as the vehicle control to disclose any effects arising from a dilution of the KHB by $1 / 3$ volume (fig. 2). Coronary effluent flow values during infusion of the three different colloid preparations are compared in figure 2. While infusion of the artificial colloid HES did not lead to any significant change versus basal or versus control, irrespective of the molecular weight, albumin caused a dramatic increase in coronary flow. This effect developed over time and apparently had not quite come to an end by 20 min of application. The exact coronary flow 
Table 1. Coronary flow during control conditions $\left(\mathrm{ml} \times \mathrm{min}^{-1} \times \mathrm{g}^{-1}\right.$, mean \pm $\mathrm{SD}, \mathrm{n}=5$ each)

\begin{tabular}{lllll}
\hline \multirow{2}{*}{ Group } & \multicolumn{4}{l}{ Time (from start of phase III) } \\
\cline { 2 - 5 } & $4 \mathrm{~min}$ & $10 \mathrm{~min}$ & $15 \mathrm{~min}$ & $20 \mathrm{~min}$ \\
\hline Control & $4.13 \pm 0.06$ & $4.18 \pm 0.21$ & $4.15 \pm 0.09$ & $4.15 \pm 0.09$ \\
Control heparinase & $4.19 \pm 0.13$ & $4.17 \pm 0.08$ & $4.16 \pm 0.10$ & $4.18 \pm 0.07$ \\
Control NO-L-Ag & $3.93 \pm 0.23$ & $3.72 \pm 0.21^{*}$ & $3.59 \pm 0.22^{*}$ & $3.49 \pm 0.19^{*}$ \\
\hline
\end{tabular}

${ }^{*} \mathrm{p}<0.05$ vs. other control groups.

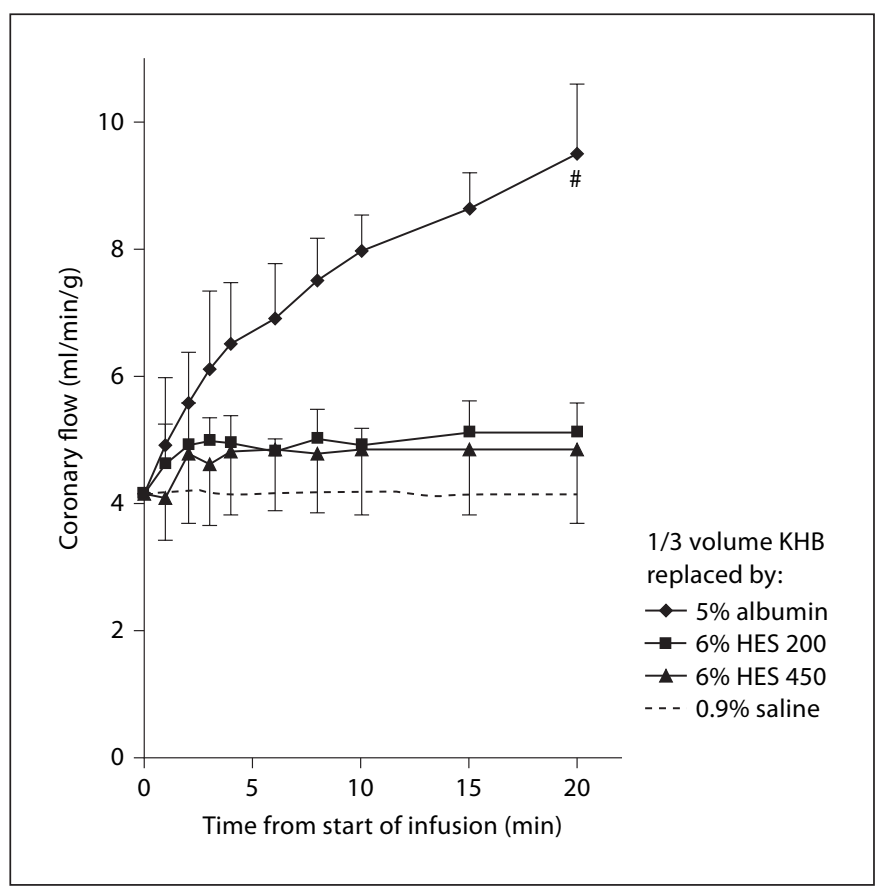

Fig. 2. Effects of colloids on coronary flow in untreated hearts (phase III, albumin, HES 200 and HES 450 groups; $\mathrm{n}=5,6$ and 5, respectively; mean values $\pm \mathrm{SD}$ ) in comparison to control conditions (phase III, control group = infusion of saline solution; $\mathrm{n}=5$; dashed line $=$ mean values, $S D$ too small for resolution). ${ }^{*} \mathrm{p}<0.05$ vs. other groups.

values at this time were $9.50 \pm 1.09,5.10 \pm 0.49$ and 4.87 $\pm 1.19 \mathrm{ml} / \mathrm{min} / \mathrm{g}$ for the albumin, HES 200 and HES 450 groups, respectively.

As can be seen in figure $3 \mathrm{a}$, the increase in flow caused by albumin was diminished by NO-L-Ag infusion or heparinase pretreatment, or by both interventions when performed in one and the same heart. The 20 -min values were $6.23 \pm 0.68,5.38 \pm 1.31$ and $5.11 \pm 1.03 \mathrm{ml} / \mathrm{min} / \mathrm{g}$ for the albumin $+\mathrm{NO}-\mathrm{L}-\mathrm{Ag}$, albumin $+\mathrm{H}$, and albumin
$+\mathrm{NO}-\mathrm{L}-\mathrm{Ag}+\mathrm{H}$ groups, respectively. Thus, while $10 \mu \mathrm{M}$ NO-L-Ag by itself did not cause full inhibition of the albumin-induced dilatation, the values after heparinase were not significantly higher than in the time-matched control heparinase group (table 1). Also, the effect of NO$\mathrm{L}-\mathrm{Ag}$ was not additive to that of heparinase in the case of albumin. In contrast, during infusion of HES 450, blocking formation of NO by application of NO-L-Ag, but not stripping away the heparan sulfates from the EG significantly suppressed the coronary flow rate (fig. $3 \mathrm{~b}$ ). The 20 -min values were $4.87 \pm 1.19,4.55 \pm 0.78,3.41 \pm 0.42$ and $3.91 \pm 1.01 \mathrm{ml} / \mathrm{min} / \mathrm{g}$ for the HES 450 , HES $450+\mathrm{H}$, HES $450+$ NO-L-Ag and HES $450+\mathrm{NO}-\mathrm{L}-\mathrm{Ag}+\mathrm{H}$ groups, respectively. This finding suggests that the big HES molecule may be able to elicit some production of $\mathrm{NO}$ via shear stress by an interaction even with a rudimentary EG. Fittingly, pretreatment with heparinase also had no significant effect on coronary flow in hearts perfused with HES $200(20 \mathrm{~min}$ value $5.10 \pm 0.49 \mathrm{ml} / \mathrm{min} / \mathrm{g}$ with and without heparinase, data not shown).

With application of $10 \mu \mathrm{M}$ NO-L-Ag preventing generation of $\mathrm{NO}$, the measured coronary flows of the albumin + NO-L-Ag and HES $450+\mathrm{NO}-\mathrm{L}-\mathrm{Ag}$ groups were still significantly different $(6.23 \pm 0.68$ and $3.41 \pm 0.42$ $\mathrm{ml} / \mathrm{min} / \mathrm{g}$ at $20 \mathrm{~min}$, respectively, $\mathrm{p}<0.05$ ).

Table 2 provides dynamic viscosities and colloid osmotic pressures of the respective perfusates. As can be seen in table 2 and figure 2, colloid-induced, flow-dependent coronary dilatation does not correlate with dynamic viscosity when colloids of a different chemical nature are compared. When perfusing with KHB plus albumin the dynamic viscosity is comparable to that pertaining to colloid-free perfusion, but flow was doubled. In contrast, the viscosity after adding $1 / 3$ volume $6 \%$ HES 450 is almost twice as high as that of $\mathrm{KHB}$, while the flow remained unchanged. Again, the flow in the HES $450+$ NO-L-Ag group was identical to that observed after $20 \mathrm{~min}$ in the control NO-L-Ag group (compare fig. $3 \mathrm{~b}$ and table 1). 


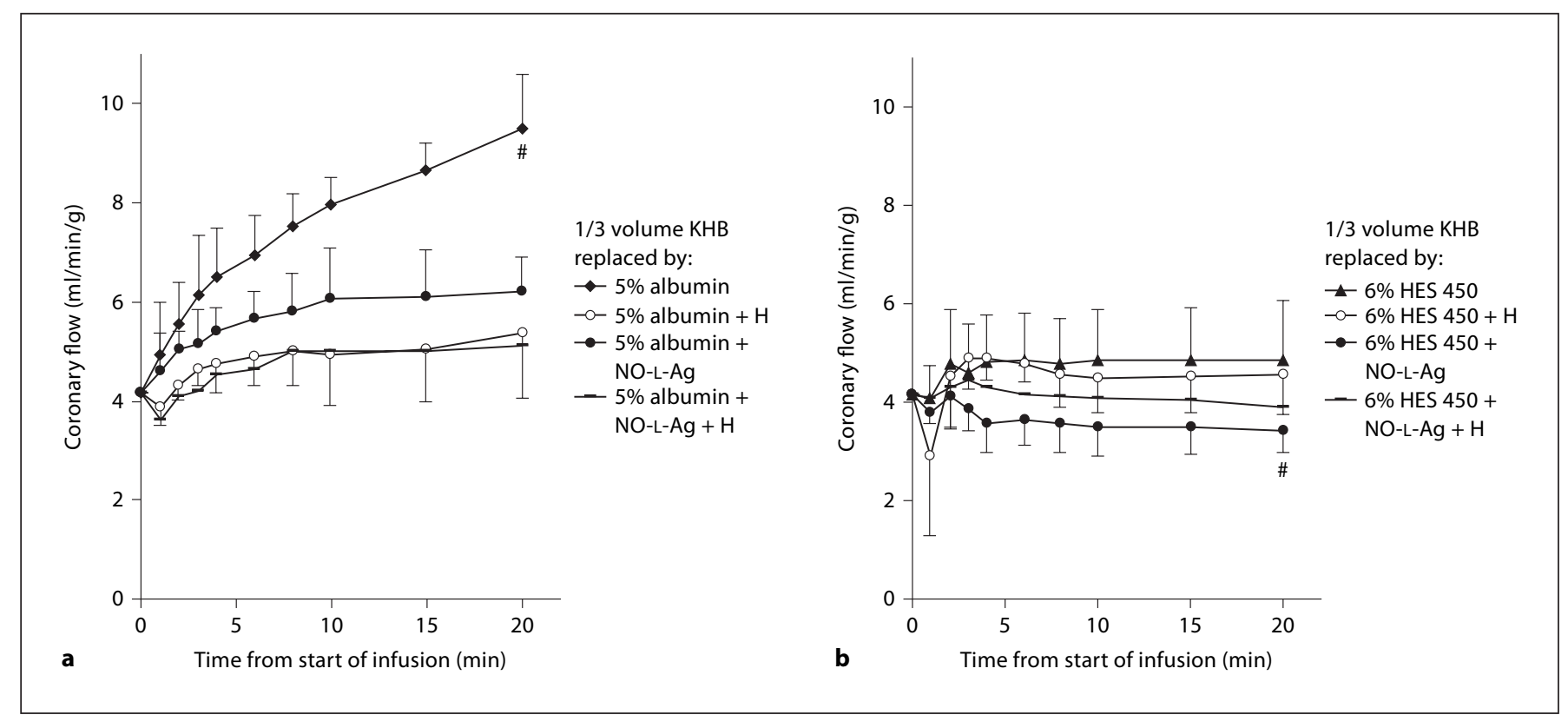

Fig. 3. Effects of albumin and HES 450 on coronary flow after cardiac pretreatment with heparinase $(\mathrm{H})$ and/or in the presence of NO-L-Ag. a Albumin, albumin $+\mathrm{H}$, albumin + NO-L-Ag and albumin + NO-L-Ag + H groups $(\mathrm{n}=5,5,8$ and 5 , respectively; mean values $\pm \mathrm{SD}) .{ }^{*} \mathrm{p}<0.05$ vs. other groups. b HES 450 , HES $450+\mathrm{H}, \mathrm{HES}$ $450+$ NO-L-Ag and HES $450+$ NO-L-Ag $+\mathrm{H}$ groups ( $\mathrm{n}=5$ each; mean values $\pm \mathrm{SD}) .{ }^{*} \mathrm{p}<0.05$ vs. HES 450 and HES $450+$ H groups.

Table 2. Dynamic viscosities and colloid osmotic pressures of the colloid-containing perfusates

\begin{tabular}{|c|c|c|}
\hline Perfusate & $\begin{array}{l}\text { Dynamic } \\
\text { viscosity, } \mathrm{cP}\end{array}$ & $\begin{array}{l}\text { Colloid osmotic } \\
\text { pressure, } \mathrm{mm} \mathrm{Hg}\end{array}$ \\
\hline КНB & 0.77 & 0.00 \\
\hline KHB with $0.9 \%$ saline $^{\mathrm{a}}$ & 0.77 & 0.00 \\
\hline KHB with $5 \%$ albumin ${ }^{a}$ & 0.83 & 5.30 \\
\hline KHB with $6 \%$ HES $200^{\mathrm{a}}$ & 1.02 & 5.80 \\
\hline KHB with $6 \%$ HES $450^{\mathrm{a}}$ & 1.24 & 4.60 \\
\hline
\end{tabular}

Colloid osmotic pressure determined with Oncometer BMT 923 (BMT Messtechnik, Berlin, Germany) at $37^{\circ} \mathrm{C}$. Kinematic viscosity measured at $37^{\circ} \mathrm{C}$ with a Viscosimeter Type D60L (Lauda Dr. R. Wobser, Lauda-Königshofen, Germany), dynamic (absolute) viscosity calculated as: dynamic viscosity $(\mathrm{cP})=$ kinematic viscosity $(\mathrm{cSt}) \times$ density $(\mathrm{g} / \mathrm{ml})$.

${ }^{\text {a }} \mathrm{KHB}$ augmented by $1 / 3$ volume of the respective solution.

The colloid osmotic pressure of perfusate containing HES 200 is larger than that of the smaller molecular weight albumin or the higher molecular weight HES 450 (table 2). However, the latter is still comparable to that of albumin, despite the approximately 6-to 7-fold difference in average molecular weight ( $66 \mathrm{vs} .450 \mathrm{kDa}$ ). The flow effects observed in figure 2 did not correlate with these colloid osmotic pressures.

Electron microscopy revealed an EG with a thickness of approximately $0.2-0.3 \mu \mathrm{m}$ in nonpretreated hearts and in hearts treated with NO-L-Ag, both in capillary vessels as well as in arteries (see fig. 4). This in situ result stands in clear contrast to the situation on a nonpretreated monolayer of HUVEC (2nd passage cells), stained by the same technique as were the hearts (fig. $4 \mathrm{~b}$ ). There is no relevant EG on HUVEC, the measured thickness being about $20 \mathrm{~nm}$. The same dimension was observed, irrespective of the state of confluence of the cultures (results not shown).

Heparinase pretreatment, at first sight, led to a destruction of the EG (fig. 5). However, at a higher magnification, a rudimentary glycocalyx could be identified in some parts of the vasculature, even after enzymatic digestion (fig. 5). This possibly represents the remaining syndecan and glypican scaffold. 
Fig. 4. Electron-microscopic views of an untreated heart (ex vivo preparation): capillary segments (a) and small artery (b). The white patches present in the intravascular zone are artifacts, due to tearing of the embedding matrix. Electron-microscopic close up of a coronary endothelial cell in situ of an untreated heart (c) and of a HUVEC in culture (d). The EG of the heart preparation has a visible thickness of about $300 \mathrm{~nm}$, in contrast to the unphysiological conditions of the cultured HUVEC, exhibiting a glycocalyx of less than $40 \mathrm{~nm}$. CEC = Coronary endothelial cell; IVS = intravascular space; $\mathrm{M}=$ myocardium; $\mathrm{N}=$ cell nucleus.

Fig. 5. Electron-microscopic view at two magnifications of a heart after enzymatic digestion of the EG with 10 IU heparinase/15 min. A rudimentary glycocalyx remained on some parts of the endothelial surface. The edema of hearts with damaged glycocalyx is clearly visible.
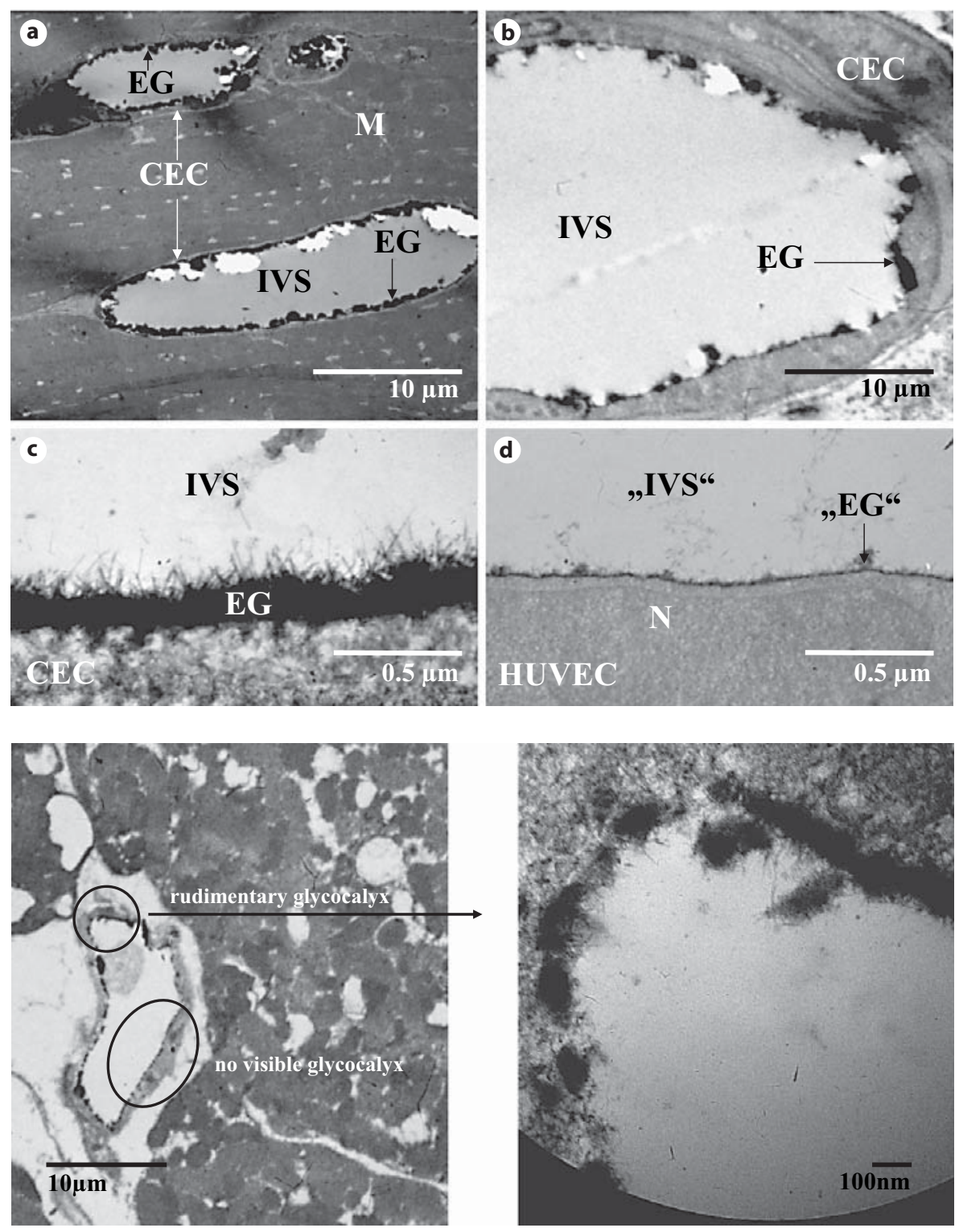

\section{Discussion}

The endothelial surface is covered by a glycocalyx consisting of glycoproteins, proteoglycans and associated glycosaminoglycan (GAG) side chains $[6,19]$. The main type of GAG on the endothelial cell surface are heparan sulfates, comprising up to $90 \%$ of the GAG pool [27]. Their function as signal transduction molecules has been extensively studied [28]. Heparan sulfate proteoglycans can be divided into three different groups on the basis of the respective protein backbone: syndecans, glypicans and perlecans [19]. The largest group on the endothelial surface, the syndecans, are the only heparan sulfate proteoglycans that penetrate the cytoplasm to interact with the cytoskeleton [29]. They have highly variable extracellular domains and highly conserved intracellular phosphorylation sites [30]. It is assumed that the syndecans transduce shear stress into cellular signals [31, 32].

In the isolated perfused organ model, we were able to demonstrate that albumin, in contrast to artificial colloids, leads to an impressive, significant increase in coronary flow in the constant pressure perfusion mode. This phenomenon seems to result largely from shear stress transmitted via the glycocalyx on the endothelial surface. 
At least in the guinea pig heart, this leads chiefly to the generation of NO, since it was possible to inhibit the flowdependent dilatation by blocking the NO synthase almost as well as by stripping away the main part of the glycocalyx. Interestingly, these two interventions were not additive in the case of albumin.

Maximal coronary flow that can be achieved in these heart preparations at $80 \mathrm{~cm} \mathrm{H}_{2} \mathrm{O}$ perfusion pressure is about $25 \mathrm{ml} / \mathrm{min} / \mathrm{g}[33,34]$. Thus, the flow increases induced by shear stress seen here were quite moderate. Whether the enhancement of basal NO production via shear stress alters coronary responses to other vasodilators (endothelium and nonendothelium dependent) was not tested in this study. Both desensitization and augmentation appear to be valid options.

Pertinently, the dilatation induced by albumin did not quite reach a steady state during our observation time of 20 min, likely due to a positive feedback mechanism: shear stress leads to NO-mediated vasodilatation, whereupon the coronary flow increases; consequently, the shear stress increases again somewhat. In this context, attention must be drawn to the fact that both, the mode of perfusion (constant pressure) and the style of preparation (incompetent mitral valve precluding the performance of any pressure-volume work), were chosen to augment such feedback possibilities. Accordingly, during constant flow perfusion supplementing perfusate with albumin elicits only a small, self-limiting drop in steady-state coronary perfusion pressure, i.e., due to negative feedback only a limited vasodilatory response is to be observed [8].

The isolated perfused heart as prepared here (Langendorff mode) per definition does not perform any pressurevolume work. Nevertheless, coronary flow is under a certain degree of metabolic control. Changes in coronary flow, of course, change oxygen delivery to the heart preparation. Thus, albumin-induced dilatation will be counteracted to some extent by an autoregulatory increase in vascular tone, while flow reduction due to perfusion with a medium of a higher viscosity $(\mathrm{KHB}+1 / 3$ volume $\mathrm{HES}$ $450)$ will elicit some reactive metabolic dilatation. However, from previous work it is known that delivery of oxygen via perfusates without hemoglobin does not limit oxygen consumption. In fact, there is considerable 'luxury' perfusion $[33,35]$. The effects of altered supply on coronary reaction are, therefore, very much attenuated and have not been considered further in the present study. Since the $\mathrm{PO}_{2}$ of all perfusates was identical (approximately $400 \mathrm{~mm} \mathrm{Hg}$ ), metabolic regulation should not have elicited flows different from those observed with KHB + vehicle (control groups receiving $0.9 \%$ saline).

Glycocalyx-Mediated Coronary Dilatation
The reason why albumin causes an effect far larger than that observed during infusion of artificial colloids could relate to a specific interaction of the natural colloid with the glycocalyx. By virtue of its amphiphilic nature, i.e., the presence of both negatively and positively charged groups in the molecule, albumin forms a complete ESL $[2,4,8,15]$. In contrast, the glycocalyx represents an exclusion zone for large neutral and anionic molecules like dextrans $\geq 70 \mathrm{kDa}[36,37]$ and it may be expected that other large molecules carrying an exclusively negative charge, such as HES, also do not interact well with an intact EG. Accordingly, an albumin-containing perfusate should 'hook' into this structure, transmitting shear stress to the vessel wall, while artificial colloids like HES, figuratively speaking, brush only against the top of the glycocalyx molecules [38]. Such a difference is reflected by the similarity in intravascular distribution spaces of HES and red blood cells in vivo, as opposed to those tracers binding to albumin $[39,40]$. This interpretation is also in line with our previous work concerning the barrier function of the EG $[4,8,17]$, which is also overproportionally enhanced by albumin versus HES [8]. Owing to the different quality of the ESL, it is understandable why there was only an insignificant mean increase in coronary flow in the HES groups in comparison to perfusion with colloid-free buffer, and why no simple relationship existed to dynamic viscosity of the various perfusates.

Notwithstanding, from comparing the coronary flows after heparinase pretreatment and during NO-L-Ag application, it can be derived that colloids are able to mediate some shear stress to the vessel wall, even after most of the negative charges have been stripped from the EG with heparinase. The difference was significant in the experiments with KHB augmented with HES 450. As demonstrated previously, heparinase is an enzyme specific for heparan sulfates and, therefore, has the ability to alter thickness $[1,3,4]$ and barrier function $[4,17,34,41]$ of the glycocalyx. However, as revealed by electron microscopy at a high magnification in this work, small regions of glycocalyx remain also after heparinase pretreatment, likely representing a scaffold of syndecans and glypicans minus side chains. Obviously, HES molecules with the high molecular weight of $450 \mathrm{kDa}$ are big enough to interact mechanically with a rudimentary glycocalyx, causing some increase in coronary flow sensitive to inhibition of the NO synthase.

Surprisingly, in the presence of NO-L-Ag, the flow with perfusate containing HES 450 did not differ from that of control hearts perfused with NO-L-Ag (see fig. 3; table 1), despite the different perfusate viscosity. Since 
NO-L-Ag is expected to inhibit both, stimulated and basal NO production, some residual dilatory mechanism must still be active for HES 450 in the absence of NO generation. The same conclusion as for HES 450 may be drawn in the case of albumin. Here too, NO-L-Ag did not fully inhibit the rise in coronary flow induced by albumin versus control. These phenomena could relate to induction of endothelium-derived hyperpolarizing factor or prostacyclin by shear stress.

Numerous studies have examined shear stress-mediated actions on cultured endothelial cells, but only few even considered the relationship between the EG and shear stress-induced effects. For example, Florian et al. [19] stated, due to qualitative staining of heparan sulfate via a fluorescent antibody in a bovine aortic endothelial cell monolayer, that they were dealing with an EG in their model. Ueda et al. [39] delivered electron-microscopic pictures of the EG in a comparable model after staining with ruthenium red. The resulting absolute thickness is not quantified, but according to the presented scale in their figures, we would estimate it to be less than $50 \mathrm{~nm}$. In contrast, by stabilizing the EG with $\mathrm{La}^{3+}$ during fixation we measured a thickness of at least $300 \mathrm{~nm}$ for the healthy, colloid-free glycocalyx, as also reported previously $[4,8,14,16]$. On the basis of our electron-microscopic images, the EG of cultured HUVEC should, at best, be comparable to that established after heparinase pretreatment of coronary vascular endothelial cells in situ. Consequently, measuring release of $\mathrm{NO}$ induced by shear stress with cultured cells can, in no way, reflect normal behavior of an intact EG. Release of NO due to shear stress in this setting could represent an interaction of the perfusate with the rudimentary glycocalyx, or it could result from direct deformation of the endothelial cell membrane by the flowing buffer. In any case, the cultured monolay- er seems an extremely poor model of the conditions in vivo, at least concerning the physiological impact of the EG in its capacity to form a competent ESL.

The discrepancy between cultured endothelial cells and the situation in vivo becomes even greater when considering a shortcoming of our perfusion model, namely the absence of plasma constituents possibly augmenting formation of the ESL by albumin. Numerous studies have suggested that albumin alone is not as effective in reducing vascular permeability as plasma and serum [42]. The same may hold true with respect to the magnitude of shear stress-mediated coronary dilatation.

In conclusion, the present work highlights the value of the physiological plasma component albumin for developing an ESL and thereby eliciting strong shear stress dependency of vascular dilatation. This interaction should help to maintain basal nutritive blood flow, possibly by strengthening natural vasomotion and reducing the likelihood of capillaries having low or no perfusion. The results thus suggest a need for reconsidering the widespread clinical use of nonphysiological substances as substitutes of plasma colloids. At least in critically ill patients, infusion of albumin would seem the better therapeutic choice.

\section{Acknowledgments}

The authors are very grateful to Ms. S. Herzmann for expert technical assistance.

Studies were supported, in part, by the GEMI Fund, Harvard Medical International, USA, and the Karolinska Institute, Stockholm, Sweden, as well as by departmental research funding provided by the Government of Bavaria (Bavarian State Ministry of Science, Research, and the Arts, Munich).

\section{References}

1 Desjardins C, Duling BR: Heparinase treatment suggests a role for the endothelial cell glycocalyx in regulation of capillary hematocrit. Am J Physiol 1990;258:H647-H654.

2 Pries AR, Secomb TW: Microvascular blood viscosity in vivo and the endothelial surface layer. Am J Physiol Heart Circ Physiol 2005; 289:H2657-H2664.

3 Pries AR, Secomb TW, Jacobs H, Sperandio M, Osterloh K, Gaehtgens P: Microvascular blood flow resistance: role of endothelial surface layer. Am J Physiol 1997;273:H2272H2279.
4 Rehm M, Zahler S, Lotsch M, Welsch U, Conzen P, Jacob M, Becker BF: Endothelial glycocalyx as an additional barrier determining extravasation of $6 \%$ hydroxyethyl starch or $5 \%$ albumin solutions in the coronary vascular bed. Anesthesiology 2004;100: 1211-1223.

5 Vink H, Duling BR: Identification of distinct luminal domains for macromolecules, erythrocytes, and leucocytes within mammalian capillaries. Circ Res 1996;79:581-589.

6 Pries AR, Secomb TW, Gaehtgens P: The endothelial surface layer. Pflügers Arch 2000; 440:653-666.
7 Constantinescu AA, Vink H, Spaan JA: Endothelial cell glycocalyx modulates immobilization of leukocytes at the endothelial surface. Arterioscler Thromb Vasc Biol 2003;23: 1541-1547.

8 Jacob M, Bruegger D, Conzen P, Rehm M, Becker BF: Contrasting effects of colloid and crystalloid resuscitation fluids on cardiac vascular permeability. Anesthesiology 2006; 104:1223-1231.

9 van den Berg BM, Vink H, Spaan JA: The endothelial glycocalyx protects against myocardial edema. Circ Res 2003;92:592-594.

Jacob/Rehm/Loetsch/Paul/Bruegger/ Welsch/Conzen/Becker 
10 Risau W: Differentiation of endothelium. FASEB J 1995;9:926-933.

11 Siegel G, Malmsten M: The role of the endothelium in inflammation and tumor metastasis. Int J Microcirc Clin Exp 1997;17:257272.

12 Vink H, Constantinescu AA, Spaan JA: Oxidized lipoproteins degrade the endothelial surface layer: implications for platelet-endothelial cell adhesion. Circulation 2000;101: 1500-1502.

13 Platts SH, Linden J, Duling BR: Rapid modification of the glycocalyx caused by ischemia-reperfusion is inhibited by adenosine A2A receptor activation. Am J Physiol Heart Circ Physiol 2003;284:H2360-H2367.

14 Gouverneur M, van den Berg B, Nieuwdorp M, Stroes E, Vink H: Vasculoprotective properties of the endothelial glycocalyx: effects of fluid shear stress. J Intern Med 2006; 259:393-400.

15 Adamson RH, Lenz JF, Zhang X, Adamson GN, Weinbaum S, Curry FE: Oncotic pressures opposing filtration across non-fenestrated rat microvessels. J Physiol 2004;557: 889-907.

16 Bruegger D, Jacob M, Rehm M, Loetsch M, Welsch U, Conzen P, Becker BF: Atrial natriuretic peptide induces shedding of the endothelial glycocalyx in the coronary vascular bed of guinea pig hearts. Am J Physiol Heart Circ Physiol 2005;289:H1993-H1999.

17 Jacob M, Bruegger D, Rehm M, Stoeckelhuber M, Welsch U, Conzen P, Becker BF: The endothelial glycocalyx affords compatibility of Starling's principle and high cardiac interstitial albumin levels. Cardiovasc Res 2006; 73:575-586.

18 Chang YS, Yaccino JA, Lakshminarayanan $S$, Frangos JA, Tarbell JM: Shear-induced increase in hydraulic conductivity in endothelial cells is mediated by a nitric oxide-dependent mechanism. Arterioscler Thromb Vasc Biol 2000;20:35-42.

19 Florian JA, Kosky JR, Ainslie K, Pang Z, Dull RO, Tarbell JM: Heparan sulfate proteoglycan is a mechanosensor on endothelial cells. Circ Res 2003;93:e136-e142.

20 Gonzalez-Castillo C, Rubio R, Zenteno-Savin $\mathrm{T}$ : Coronary flow-induced inotropism is modulated by binding of dextrans to the endothelial luminal surface. Am J Physiol Heart Circ Physiol 2003;284:H1348-H1357.
21 Kuchan MJ, Frangos JA: Role of calcium and calmodulin in flow-induced nitric oxide production in endothelial cells. Am J Physiol 1994;266:C628-C636.

22 Mochizuki S, Vink H, Hiramatsu O, Kajita T, Shigeto F, Spaan JA, Kajiya F: Role of hyaluronic acid glycosaminoglycans in shear-induced endothelium-derived nitric oxide release. Am J Physiol Heart Circ Physiol 2003; 285:H722-H726.

23 Rubanyi GM, Romero JC, Vanhoutte PM: Flow-induced release of endothelium-derived relaxing factor. Am J Physiol 1986;250: H1145-H1149.

24 Kohler R, Heyken WT, Heinau P, Schubert R, Si H, Kacik M, Busch C, Grgic I, Maier T, Hoyer J: Evidence for a functional role of endothelial transient receptor potential V4 in shear stress-induced vasodilatation. Arterioscler Thromb Vasc Biol 2006;26:14951502 .

25 Heindl B, Zahler S, Welsch U, Becker BF: Disparate effects of adhesion and degranulation of platelets on myocardial and coronary function in postischaemic hearts. Cardiovasc Res 1998;38:383-394.

26 Vogel J, Sperandio M, Pries AR, Linderkamp $\mathrm{O}$, Gaehtgens P, Kuschinsky W: Influence of the endothelial glycocalyx on cerebral blood flow in mice. J Cereb Blood Flow Metab 2000;20:1571-1578

27 Ihrcke NS, Wrenshall LE, Lindman BJ, Platt JL: Role of heparan sulfate in immune system-blood vessel interactions. Immunol Today 1993;14:500-505.

28 Turnbull J, Powell A, Guimond S: Heparan sulfate: decoding a dynamic multifunctional cell regulator. Trends Cell Biol 2001;11:7582 .

29 Asundi VK, Carey DJ: Self-association of Nsyndecan (syndecan-3) core protein is mediated by a novel structural motif in the transmembrane domain and ectodomain flanking region. J Biol Chem 1995;270:26404-26410.

30 Bernfield M, Kokenyesi R, Kato M, Hinkes MT, Spring J, Gallo RL, Lose EJ: Biology of the syndecans: a family of transmembrane heparan sulfate proteoglycans. Annu Rev Cell Biol 1992;8:365-393.

31 Pohl U, Herlan K, Huang A, Bassenge E: EDRF-mediated shear-induced dilation opposes myogenic vasconstriction in small rabbit arteries. Am J Physiol 1991;261: H2016-H2023.
32 Tarbell JM, Pahakis MY: Mechanotransduction and the glycocalyx. J Intern Med 2007; 259:339-350.

33 Bunger R, Haddy FJ, Querengasser A, Gerlach E: An isolated guinea pig heart preparation with in vivo like features. Pflügers Arch 1975;353:317-326.

34 Leipert B, Becker BF, Gerlach E: Different endothelial mechanisms involved in coronary response to known vasodilators. Am J Physiol Heart Circ Physiol 1992;262:H1676H1683.

35 Buenger R, Haddy FJ, Gerlach E: Coronary response to dilating substances and competing inhibition by theophylline in the isolated perfused guinea pig heart. Pflügers Arch 1975;358:213-224.

36 Jacob M, Conzen P, Finsterer U, Krafft A, Becker BF, Rehm M: Technical and physiological background of plasma volume measurement with indocyanine green: a clarification of misunderstandings. J Appl Physiol 2007;102:1235-1242. DOI: 10.1152/japplphysiol.00740.2006.

37 Tschaikowsky K, Meisner M, Durst R, Rugheimer E: Blood volume determination using hydroxyethyl starch: a rapid and simple intravenous injection method. Crit Care Med 1997;25:599-606.

38 Mulivor AW, Lipowsky HH: Role of glycocalyx in leukocyte-endothelial cell adhesion. Am J Physiol Heart Circ Physiol 2002;283: H1282-H1291.

39 Ueda A, Shimomura M, Ikeda M, Yamaguchi R, Tanishita K: Effect of glycocalyx on shear-dependent albumin uptake in endothelial cells. Am J Physiol Heart Circ Physiol 2004;287:H2287-H2294.

40 Vink H, Duling BR: Capillary endothelial surface layer selectively reduces plasma solute distribution volume. Am J Physiol Heart Circ Physiol 2000;278:H285-H289.

41 van Haaren P, VanBavel E, Vink H, Spaan JA: Localization of the permeability barrier to solutes in isolated arteries by confocal microscopy. Am J Physiol Heart Circ Physiol 2003;285:H2848-H2856.

42 Huxley VH, Curry FE, Powers MR, Thipakorn B: Differential action of plasma and albumin on transcapillary exchange of anionic solute. Am J Physiol 1993;264:H1428H1437. 